\title{
Corrosion of ruthenium dioxide based cathodes in alkaline medium caused by reverse currents
}

\author{
Susanne Holmin, Lars-Åke Näslund, Arni Sigurdur Ingason, Johanna Rosén and Erik \\ Zimmerman
}

\section{Linköping University Post Print}

\section{Tweet}

N.B.: When citing this work, cite the original article.

Original Publication:

Susanne Holmin, Lars-Åke Näslund, Arni Sigurdur Ingason, Johanna Rosén and Erik Zimmerman, Corrosion of ruthenium dioxide based cathodes in alkaline medium caused by reverse currents, 2014, Electrochimica Acta, (146), 30-36.

http://dx.doi.org/10.1016/j.electacta.2014.09.024

Copyright: Elsevier

http://www.elsevier.com/

Postprint available at: Linköping University Electronic Press

http://urn.kb.se/resolve?urn=urn:nbn:se:liu:diva-113016 


\title{
Corrosion of ruthenium dioxide based cathodes in alkaline medium caused by reverse currents
}

Susanne Holmin ${ }^{\mathrm{a}, \mathrm{b},{ }^{*}}$ Lars-Åke Näslund, ${ }^{\mathrm{c}}$ Árni S. Ingason, ${ }^{\mathrm{c}}$ Johanna Rosen, ${ }^{\mathrm{c}}$ and Erik Zimmerman $^{\mathrm{a}}$

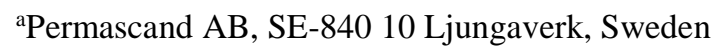

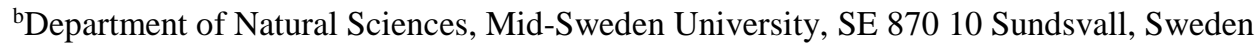

'Materials Design, Thin Film Physics Division, Department of Physics, Chemistry, and Biology (IFM),

Linköping University, SE-58183 Linköping, Sweden

Keywords: Hydrogen evolution, $\mathrm{RuO}_{2}$ coatings, Phase transformation, Polarity inversion, Corrosion.

\begin{abstract}
A reverse current obtained during power shutdowns in industrial processes, such as chloralkali production or alkaline water electrolysis, is deleterious for hydrogen evolving ruthenium dioxide $\left(\mathrm{RuO}_{2}\right)$ based cathodes. It has been observed that $\mathrm{RuO}_{2}$ coatings after a power shutdown, necessary for e.g. maintenance, are severely damaged unless polarization rectifiers are employed. In this work we show why these types of cathodes are sensitive to reverse currents, i.e. anodic currents, after hydrogen evolution. $\mathrm{RuO}_{2}$ coatings deposited on nickel substrates were subjected to different electrochemical treatments such as hydrogen evolution, oxygen evolution, or reverse currents in $8 \mathrm{M} \mathrm{NaOH}$ at $90{ }^{\circ} \mathrm{C}$. Polarity inversion was introduced after hydrogen evolution to simulate the effect of reverse currents. Because of chemical interaction with hydrogen, a significant amount of the $\mathrm{RuO}_{2}$ coating was transformed into hydroxylated species during cathodic polarization. Our study shows that these hydroxylated phases are highly sensitive to electrochemical corrosion during anodic polarization after extended hydrogen evolution.
\end{abstract}

*Corresponding author. Phone: +46 691355 17; fax: +46 69133040.

E-mail address: susanne.holmin@permascand.com 


\section{Introduction}

Ruthenium dioxide $\left(\mathrm{RuO}_{2}\right)$ or mixtures of $\mathrm{RuO}_{2}$ and other metal oxides $\left(\mathrm{TiO}_{2}, \mathrm{IrO}_{2}\right.$ etc.), deposited on a titanium (Ti) support, have successfully been used as catalytic and durable coatings for decades in different industrial processes such as chlorine or oxygen gas production. These types of electrodes are often referred to as dimensionally stable anodes $\left(\mathrm{DSA}^{\circledR}\right) . \mathrm{RuO}_{2}$-based coatings have also found practical applications as a catalyst for hydrogen evolution in chlor-alkali production and alkaline water electrolysis [1]. $\mathrm{RuO}_{2}$ is then usually deposited on nickel (Ni) substrates because of higher corrosion resistance of $\mathrm{Ni}$, compare to e.g. Ti, in highly concentrated alkaline electrolyte at elevated temperatures.

The most challenging drawback for $\mathrm{RuO}_{2}$-based cathodes is not activity or duration for hydrogen evolution but reverse currents at power shutdowns. For example, when the chloralkali process is interrupted, e.g. for maintenance, a reverse current will flow in the electrochemical cell caused by the change in equilibrium, i.e. hypochlorite and other active chlorine species close to the anode surface starts to reduce. As a consequence the $\mathrm{RuO}_{2}$-based coating on the cathode starts to degrade, which is suggested being caused by oxidation [1-3]. By introducing polarization rectifiers, the effect of reverse currents can be minimized. A cathodic potential is then applied large enough to protect the $\mathrm{RuO}_{2}$ catalyst from anodic dissolution during a power shutdown [2].

Although several authors have reported loss of catalyst material as an effect of reverse currents [3-6], the long-term stability of $\mathrm{RuO}_{2}$-based coatings has not been well studied. In the previous studies reverse current was introduced by polarity inversion, i.e. repetitive cycling of the current or potential between the hydrogen and oxygen evolution reaction or by applying an anodic current after extensive hydrogen evolution. Furthermore, different investigations have shown substantial changes in $\mathrm{RuO}_{2}$ and other mixed oxides after hydrogen evolution. For example, increased voltammetric charge and activation of the catalyst was found with cyclic voltammetry [7-9]. It was suggested that wetting of active sites or hydroxylation of $\mathrm{RuO}_{2}$ caused the activation process. Studies with X-ray diffraction (XRD) showed an expansion of the $\mathrm{RuO}_{2}$ crystal lattice caused by hydrogen absorption into the rutile structure while exposed to hydrogen evolution in acidic medium [10]. In addition, other XRD studies have found irreversible decrease and shift of the rutile diffraction peaks for $\mathrm{RuO}_{2}$ exposed to an alkaline electrolyte $[3,11]$. Roughening of the electrode surface area caused by strong 
hydrogen evolution has also been reported from studies using atomic force microscopy [12] and scanning electron microscopy [13]. All of these studies indicate that $\mathrm{RuO}_{2}$ is unstable during hydrogen evolution.

According to thermodynamics, $\mathrm{RuO}_{2}$ exposed to an alkaline electrolyte suggests being reduced to metallic ruthenium during hydrogen evolution $[14,15]$, however, several authors have in the past used X-ray photoelectron spectroscopy (XPS) with the conclusion that metallic ruthenium does not form $[8,16,17]$. In contradiction to earlier conclusions, we have in a recent work showed that metallic ruthenium, in fact, is formed during hydrogen evolution in an alkaline electrolyte and at high current density [18]. The study further shows that the $\mathrm{RuO}_{2}$ coating, prior to metallic $\mathrm{Ru}$ formation, is subjected to a transformation into ruthenium oxyhydroxide $\left(\mathrm{RuO}(\mathrm{OH})_{2}\right)$. Earlier, authors have suggested that $\mathrm{RuO}_{2}$ is partly reduced through hydration or hydroxylation during hydrogen evolution $[3,9,11,16]$, although never studied in detail. Our detailed material characterization support hydroxylation, however not through a reduction process but instead via a nonelectrochemical process induced by hydrogen incorporation into the $\mathrm{RuO}_{2}$ rutile crystal structure [18].

The influence of reverse currents on the stability of the formed $\mathrm{RuO}(\mathrm{OH})_{2}$ has, to our best knowledge, never been studied in detail before. Therefore, we have applied several material characterization techniques, such as scanning electron microscopy (SEM), X-ray diffraction (XRD), and X-ray fluorescence (XRF), to study the corrosion behavior of $\mathrm{RuO}_{2}$-based coatings in a strong alkaline environment after different electrochemical treatments. The sample treatments include the hydrogen evolution reaction (HER), the oxygen evolution reaction (OER), and in addition a sequence of alternating HER and OER for the effect of reverse currents. Understanding the corrosion mechanism for $\mathrm{RuO}_{2}$-based cathodes during working conditions, such as hydrogen evolution in alkaline environment, is important before further improvements of the activity and stability of said coatings can be developed. 


\section{Experimental section}

\subsection{Electrode preparation}

The spin coating technique was implemented to assure that reproducible samples were obtained [19,20]. Nickel disks (Ni-201) with a diameter of $25 \mathrm{~mm}$ and thickness of $1 \mathrm{~mm}$ were used as substrates. Prior to coating, the disks were blasted with $\mathrm{Al}_{2} \mathrm{O}_{3}$ particles (diameter: 50-75 $\mu \mathrm{m}$ ). After the blasting pre-treatment the disks were ultrasonically cleaned in Milli-Q water for $10 \mathrm{~min}$ at $30{ }^{\circ} \mathrm{C}$ and finally rinsed with acetone.

A coating solution containing $0.60 \mathrm{M} \mathrm{Ru}$ in 1-propanol was prepared by dissolving $7.450 \mathrm{~g}$ $\mathrm{RuCl}_{3} \times \mathrm{nH}_{2} \mathrm{O}$ (40.27 wt-\% Ru, Heraeus) to a final volume of $50 \mathrm{ml}$ in 1-propanol (Fischer Scientific). $100 \mu \mathrm{l}$ of the coating solution was applied to cover the Ni surface and left for 2.5 min. A uniform distribution of coating solution over the Ni substrate was then obtained through a spin coater from Micro Systems Ltd for $30 \mathrm{~s}$ with a rotation speed of $4500 \mathrm{rpm}$. The electrodes were then left to dry in air for $5 \mathrm{~min}$, followed by additional $5 \mathrm{~min}$ at $80{ }^{\circ} \mathrm{C}$. Thermal decomposition of $\mathrm{RuCl}_{3}$ to $\mathrm{RuO}_{2}$ was performed at $500{ }^{\circ} \mathrm{C}$ for $12 \mathrm{~min}$. The solution application, drying and calcination procedure was repeated until four layers of $\mathrm{RuO}_{2}$ were deposited on each Ni disk. The heat treatment at $500{ }^{\circ} \mathrm{C}$ was prolonged to be one hour during the last coating cycle. With this method, $\mathrm{RuO}_{2}$-coated $\mathrm{Ni}$ electrodes were obtained with a final metal loading of $4.54 \pm 0.17 \mathrm{~g} \mathrm{Ru} \mathrm{m}^{-2}$. Prior to each electrochemical measurement, the electrode was cut to a size of $3.1 \mathrm{~cm}^{2}$ and attached to a conductor; a $25 \mathrm{~cm}$ long Ni rod (diam. $1.5 \mathrm{~mm}$ ) welded to the top end of the electrode.

\subsection{Electrode characterization}

The microstructure of the coating surfaces was studied using a LEO 1550 SEM and a SIGMA HV FEG-SEM, both systems from Zeiss, operated at $20 \mathrm{kV}$ accelerator voltages. The latter was used to acquire high-resolution images of the electrode surface. A Versa 3D DualBeam microscope from FEI was used for cross-section images. Prior to ion beam milling, platinum was deposited on the electrode surface.

The electrochemical experiments required that a current feeder had to be welded on top of each $\mathrm{RuO}_{2}$-coated Ni electrode. When the current feeders were removed after the electrochemical tests the top of the electrodes were slightly damaged, e.g. through removal of small part of the coating/substrate. Direct weight measurements, to determine the coating loss, were therefore not appropriate. Instead X-ray fluorescence measurements were performed 
using the portable element analyzer NITON XLT898 from Thermo Scientific. The intensity of the $\mathrm{Ru} \mathrm{K}$ a peak was correlated to the coating amount obtained in mass Ru per area $\left(\mathrm{g} \mathrm{Ru} \mathrm{m}^{-}\right.$ ${ }^{2}$ ) using six calibration samples with varying amount of coating layers of $\mathrm{RuO}_{2}$ deposited on $\mathrm{Ni}$ substrates prepared using the spin coating technique as described earlier. For the calibration samples the amount of coating, in mass Ru per area, is determined through the actual weigh of the $\mathrm{RuO}_{2}$ coating. An uncoated Ni disk was used as a blank. The Ru content of the electrodes was determined through the average of four XRF measurements at random selected spots before and after each electrochemical test using the calibration curve. Coating loss was calculated in weight-\% Ru after each electrochemical test.

X-ray diffraction analysis was performed with an X'pert XRD system from Panalytical using Ni-filtered $\mathrm{Cu} \mathrm{K}_{\alpha}$ radiation. Symmetric $\theta-2 \theta$ scans were performed using normal BraggBrentano geometry. The sample preparation described in section 2.1 generates coatings that are built up by nanoparticles (see Fig. 1d) and the average particle size could be determined through the Scherrer equation $[21,22]$ using the full width of half maximum (fwhm) and the shape factor $\mathrm{K}=0.9$ for the $\mathrm{RuO}_{2}$ (110) reflection.

\subsection{Electrochemical measurements}

The electrochemical measurements were performed in $8 \mathrm{M} \mathrm{NaOH}$ at $90.0 \pm 0.2{ }^{\circ} \mathrm{C}$ using an electrochemical cell with a three-electrode configuration where the $\mathrm{RuO}_{2} / \mathrm{Ni}$ sample, a Nimesh, and a standard calomel electrode (sat. $\mathrm{KCl}$ ) from Radiometer Copenhagen were used as a working electrode, a counter electrode, and a reference electrode, respectively. The working and counter electrodes were placed at a distance of forty $\mathrm{mm}$ from each other while the reference electrode was placed in an external compartment, which was connected via a tube to a Luggin capillary. The tip of the capillary was placed two $\mathrm{mm}$ from the surface of the working electrode to minimize the effect from the IR-drop in the electrolyte, but not too close to disturb the current distribution. No further IR-correction was used during the experiments. The electrochemical cell was prepared with a newly made sample and filled with fresh electrolyte prior to each electrochemical test. The electrolyte was prepared from $\mathrm{NaOH}$ pellets (reagent analytical grade, Scharlau) dissolved in Milli-Q water and was stirred continuously during each experiment. Although $\mathrm{NaOH}$ of analytical grade was used, impurities in the $\mathrm{NaOH}$ pellets (mainly $\mathrm{Pb}$ and $\mathrm{Fe}$ ) were released into the electrolyte and some of it was deposited on the electrode surface during cathodic polarization. However, reducing the amount of impurities did not have any influence on the corrosion process during polarity 
inversion. Analytical grade $\mathrm{NaOH}$ pellets, without additional purification, were therefore used for the electrochemical experiments presented in this report. Other possible sources of relevant impurities were scrutinized and the amounts of impurities were, thus, reduced to insignificant levels.

The deterioration of the $\mathrm{RuO}_{2}$ coating was studied after different electrochemical treatments. Galvanostatic polarization was applied to produce hydrogen or oxygen gas at -6.4 and +6.4 $\mathrm{kA} \mathrm{m}^{-2}$, respectively. A polarity inversion test was used to simulate the effect of reverse currents during power shutdowns [4]. The current density was then cycled between cathodic $\left(-6.4 \mathrm{kA} \mathrm{m}^{-2}, 30 \mathrm{~min}\right)$ and anodic $\left(+6.4 \mathrm{kA} \mathrm{m}^{-2}, 30 \mathrm{~min}\right)$ polarization for six hours.

Cyclic voltammetry was performed with five repetitive scans between -1.2 to $+0.5 \mathrm{~V}$ vs. SCE, immediately after cathodic $\left(-6.4 \mathrm{kA} \mathrm{m}^{-2}, 2 \mathrm{~h}\right)$ or anodic $\left(+6.4 \mathrm{kA} \mathrm{m}^{-2}, 2 \mathrm{~h}\right)$ polarization. The scan rate was set to $20 \mathrm{mV} / \mathrm{s}$. All electrochemical measurements were performed with an SI 2187 Electrochemical Interface potentiostat from Solartron Analytical.

\subsection{Ultraviolet (UV) absorption spectrophotometry}

UV-VIS absorption spectrophotometry was performed in the 350-600 $\mathrm{nm}$ wavelength range using an UV-1800 Shimadzu spectrophotometer. 


\section{Results and discussion}

\subsection{Morphological structure of $\mathrm{RuO}_{2} / \mathrm{Ni}$ coatings}

Fig. 1 shows a typical example of a spin coated disk electrode (diameter $25 \mathrm{~mm}$ ) with $\mathrm{RuO}_{2}$ deposited on a Ni substrate. The coating appears rather compact on a microscale and lacks the mud-cracked pattern usually obtained by other coating solution application techniques like brushing, spraying, or dipping [19] (Fig. 1b). Nevertheless, the coating is porous on a nanoscale and contains of small $\mathrm{RuO}_{2}$ nanoparticles with a size of roughly $15-20 \mathrm{~nm}$ as shown in the high-resolution SEM (Fig. 1d). The average size of the $\mathrm{RuO}_{2}$ nanoparticles is confirmed to be around $15 \mathrm{~nm}$, as determined through the Scherrer equation applied on the $\mathrm{RuO}_{2}$ (110) reflection.

Blasting pre-treatment is crucial to obtain acceptable adhesion strength of the $\mathrm{RuO}_{2}$ coating to the Ni substrate. The disadvantage is, however, a rough coating surface with peaks and valleys (Fig. 1b), where thicker coating is obtained in the valleys compared to the peaks (Fig. 1c). The cross-section SEM image shows that the coating in the study varies from 0.4 to 1.4 $\mu \mathrm{m}$ at the thinnest and thickest regions, respectively. Still, the spin coating technique employed in this study generates a reproducible coating amount of $4.54 \pm 0.17 \mathrm{~g} \mathrm{Ru} \mathrm{m}^{-2}$.
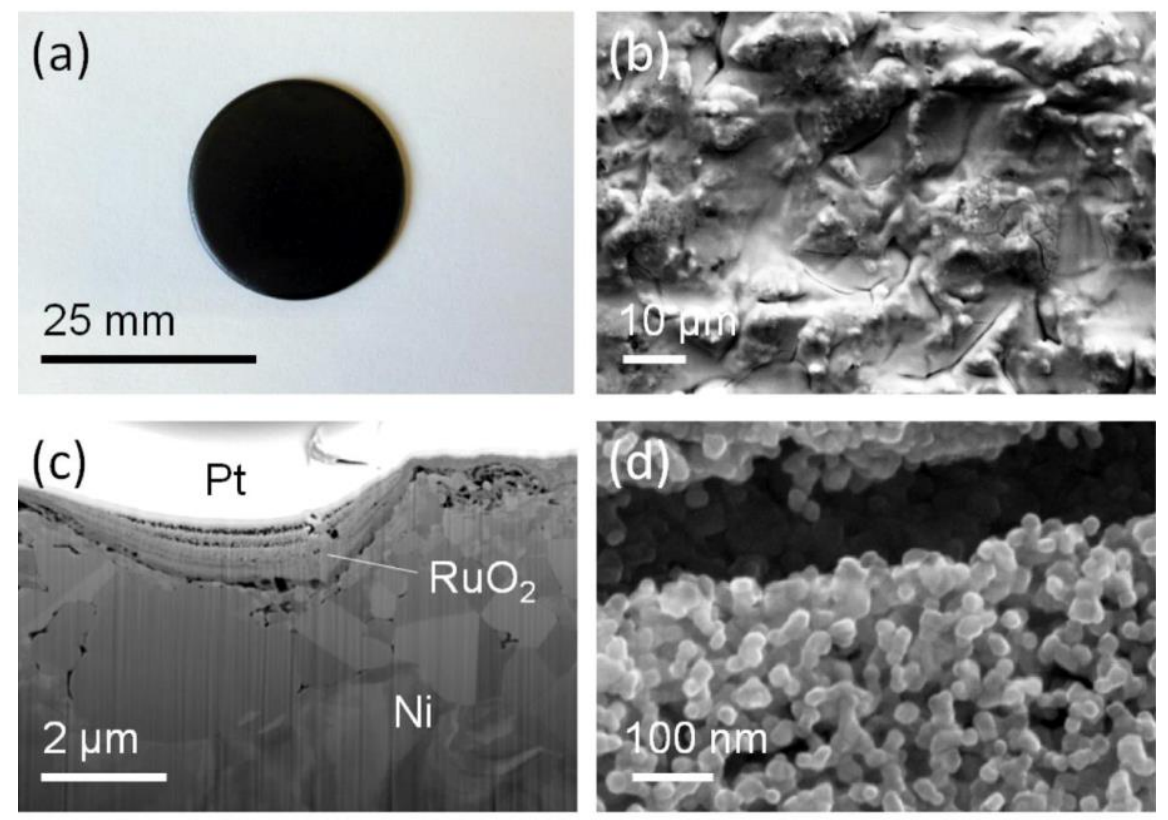

Fig. 1. $\mathrm{RuO}_{2}$-coated nickel disk electrode at different length scales: (a) on a mm-scale, (b) on a microscale, (c) a cross-section of the coating, and (d) nanostructure of $\mathrm{RuO}_{2}$ particles. The cross-section image was obtained after Pt deposition on the electrode surface followed by ion beam milling. 


\subsection{Effect of HER, OER, and reverse currents}

Figure 2-3 present losses of coatings, measured with XRF and illustrated through SEM, respectively, as examples of the effect of the different electrochemical treatments performed in $8 \mathrm{M} \mathrm{NaOH}$ at $90{ }^{\circ} \mathrm{C}$. Only small coating losses (<10 wt-\% Ru) were obtained after plain anodic or cathodic polarization (0.5-6 hours). The coating loss is an effect from mechanical erosion caused by strong gas evolution, which introduces small cracks in the coating structure and, as seen in Fig. 3b, even causes loss of coating fragments as flakes from the top layer. On the other hand, when polarity inversion was introduced immediately after the hydrogen evolution the samples show extensive loss of coating material. Fig. 2 show that about 50 wt$\%$ of the $\mathrm{RuO}_{2}$ coating was lost when the current density was cycled between the cathodic and anodic region using the polarity inversion test as described in the Experimental Section.

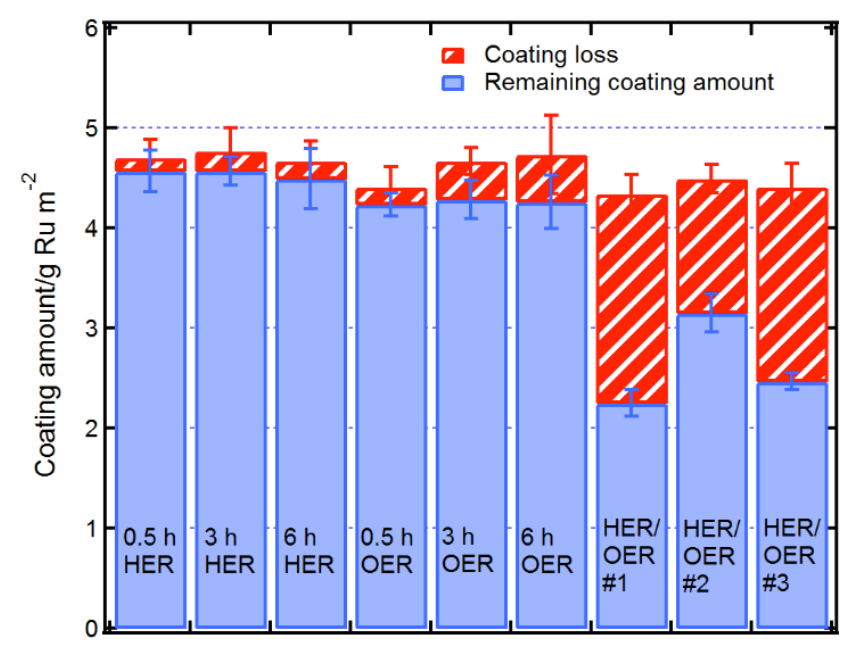

Fig. 2. Example of coating losses measured with $\mathrm{XRF}$ for spin coated $\mathrm{RuO}_{2} / \mathrm{Ni}$ electrodes

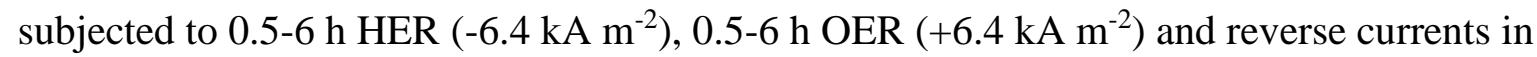
different cycled polarity inversion tests (HER/OER). HER/OER\#1: the electrode was cycled between -6.4 and $+6.4 \mathrm{kA} \mathrm{m}^{-2}$ in a polarity inversion test, HER/OER\#2: the electrode was cycled between $-6.4 \mathrm{kA} \mathrm{m}^{-2}$ and $0.0026 \mathrm{kA} \mathrm{m}^{-2}$. 1, HER/OER\#3: the electrode was cycled between -6.4 and $+6.4 \mathrm{kA} \mathrm{m}^{-2}$, but interrupted after 3.5 cycles and, thus, ending the test with a cathodic step in the polarity inversion test. Electrolyte: $8 \mathrm{M} \mathrm{NaOH}$ at $90{ }^{\circ} \mathrm{C}$. The error bars show the standard deviation from four measurements at random selected spots on each sample. 

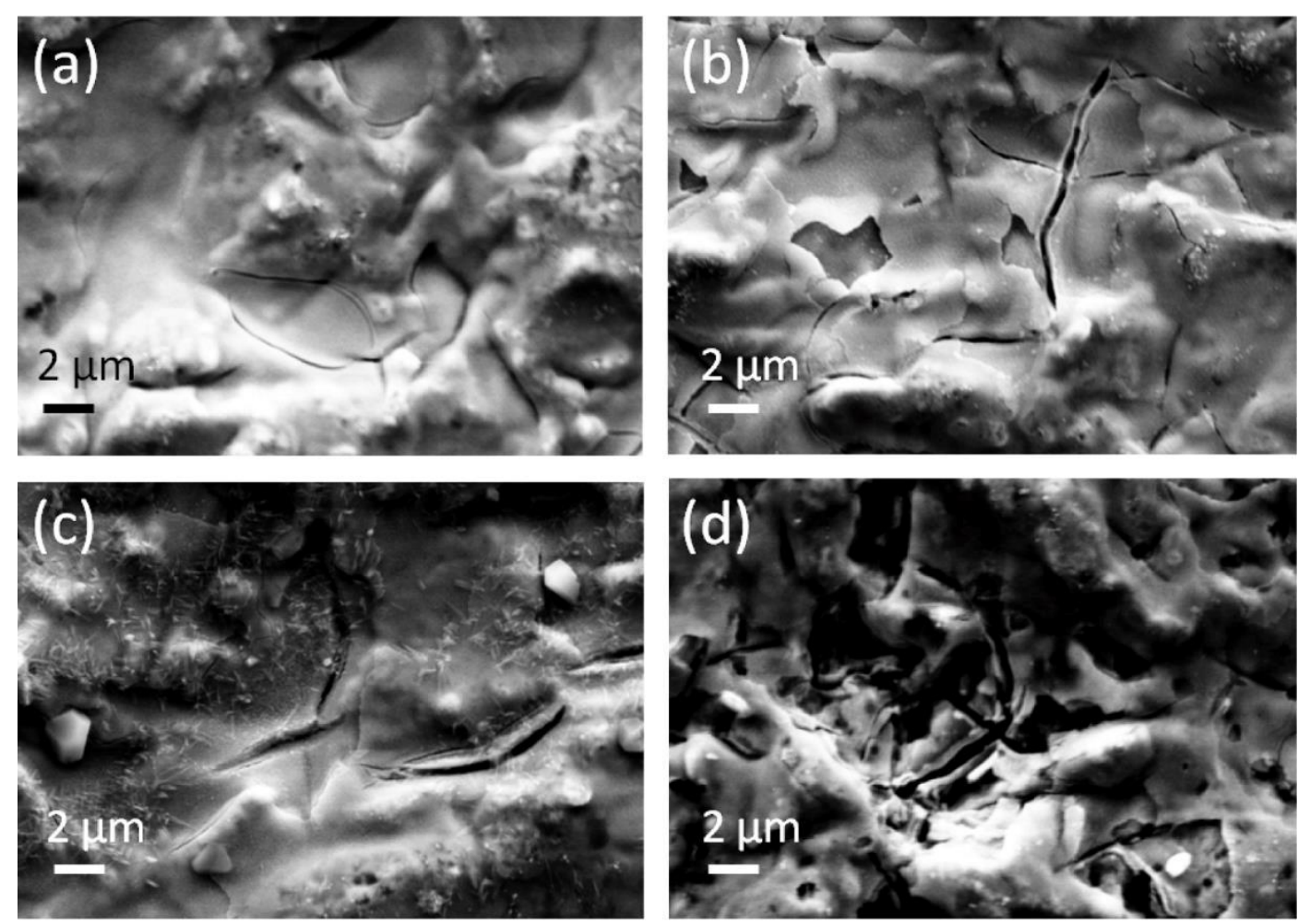

Fig. 3. SEM images for spin coated $\mathrm{RuO}_{2} / \mathrm{Ni}$ electrodes subjected to different electrochemical tests: (a) a pristine coating, (b) after $6 \mathrm{~h}$ OER (+6.4 $\left.\mathrm{kA} \mathrm{m}^{-2}\right)$, (c) after $6 \mathrm{~h}$ HER $\left(-6.4 \mathrm{kA} \mathrm{m}^{-2}\right)$, and (d) after a cycled polarity inversion test.. Electrolyte: $8 \mathrm{M} \mathrm{NaOH}$ at $90{ }^{\circ} \mathrm{C}$.

Cyclic voltammetry revealed that different corrosion processes occurred depending on the previously applied electrochemical treatment (cathodic or anodic polarization). The applied potential was cycled five times between -1.2 and $+0.5 \mathrm{~V}$ vs. SCE, i.e. between the hydrogen and oxygen evolution reaction, respectively, as shown in Fig. 4. The most noticeable is the first scan of the sample exposed to extensive hydrogen evolution. A large oxidation peak appears at about $-1.05 \mathrm{~V}$ vs. SCE caused by re-oxidation of hydrogen gas trapped inside the nanoporous coating structure [6,23]. More important is, however, the oxidation peak at about $+0.15 \mathrm{~V}$ vs. SCE indicating oxidation of $\mathrm{Ru}^{4+}$ to $\mathrm{Ru}^{6+}$, which suggests formation of ruthenate ions, $\mathrm{RuO}_{4}{ }^{2-}[6,24,25]$. The $\mathrm{RuO}_{4}{ }^{2-}$ formation is also observed in the first cycle of the reference sample, which is a consequence of that the cyclic voltammetry starts on the HER side. This is not the case after extensive oxygen evolution.

Furthermore, it is obvious that the $\mathrm{RuO}_{2}$ coating also contains $\mathrm{Ni}$ in some form as the oxidation peak for $\mathrm{Ni}^{2+} / \mathrm{Ni}^{3+}$ at about $+0.30 \mathrm{~V}$ vs. SCE is observed in the cyclic voltammetry of all three samples and, in addition, the $\mathrm{Ni}^{0} / \mathrm{Ni}^{2+}$ peak at $-0.85 \mathrm{~V}$ in the first scan of the HER 
(2 h) sample [6,26,27]. Nickel content in $\mathrm{RuO}_{2}$ coatings applied on $\mathrm{Ni}$ substrates has been confirmed with XPS [18]. The study showed that a $\mathrm{RuO}_{2}$ coating of a newly made electrode has a substantial amount of nickel oxide $(\mathrm{NiO})$, which after exposure to hydrogen evolution transforms into $\mathrm{Ni}(\mathrm{OH})_{2}$ and metallic $\mathrm{Ni}$. The $\mathrm{Ni}^{2+} / \mathrm{Ni}^{3+}$ peak in cyclic voltammetry shown in Fig. 4 can therefore be associated with the transformation from $\mathrm{NiO}$ to nickel oxyhydroxide $(\mathrm{NiOOH})$. When the potential is scanned in the reverse direction, a corresponding $\mathrm{Ni}^{3+} / \mathrm{Ni}^{2+}$ reduction peak appears at about $+0.10 \mathrm{~V}$ vs. SCE. The presence of the $\mathrm{Ni}^{0} / \mathrm{Ni}^{2+}$ peak in the HER (2 h) sample supports the XPS study showing that $\mathrm{NiO}$ is reduced to metallic Ni during extensive hydrogen evolution. Although present in the $\mathrm{RuO}_{2}$ coating, we have confirmed that different amount of $\mathrm{Ni}$ in the $\mathrm{RuO}_{2}$ coating does not significantly influence on the corrosion process of the $\mathrm{RuO}_{2}$ coating.

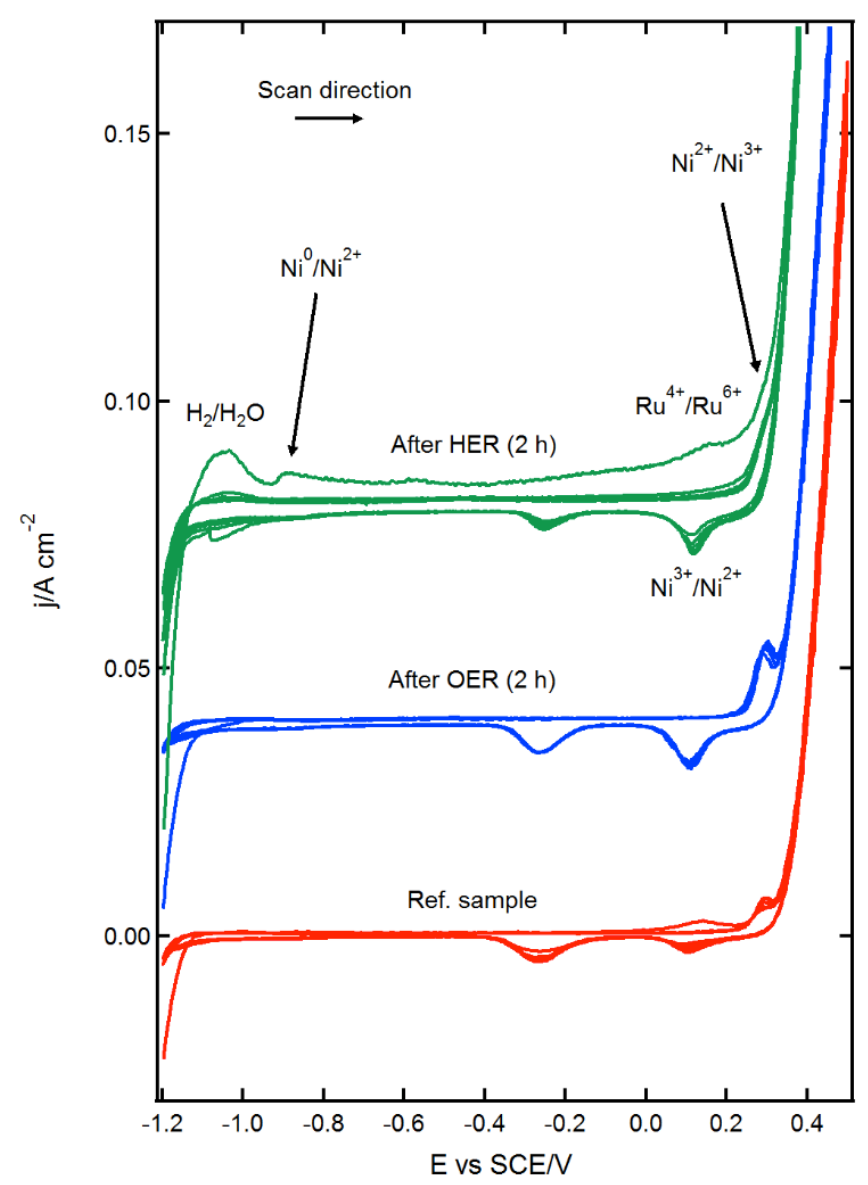

Fig. 4. Cyclic voltammetry measured for $\mathrm{RuO}_{2} / \mathrm{Ni}$ electrodes subjected to either OER $(+6.4$ $\mathrm{kA} \mathrm{m}{ }^{-2}$ ) or HER $\left(-6.4 \mathrm{kA} \mathrm{m}^{-2}\right)$ for two hours in $8 \mathrm{M} \mathrm{NaOH}$ at $90{ }^{\circ} \mathrm{C}$. A voltammogram for a reference $\mathrm{RuO}_{2} / \mathrm{Ni}$ electrode is included for comparison. For clarity the curves for the OER and HER samples are offset by 0.4 and $0.8 \mathrm{~A} / \mathrm{cm}^{2}$, respectively. 
A reduction peak at about $-0.25 \mathrm{~V}$ vs. SCE appears in the reverse scan direction in all three cyclic voltammograms. This peak is suggested to be the reduction of peroxide ions produced during extensive oxygen evolution $[23,28]$ and is therefore not related to corrosion of the electrode material.

Figure 5, which shows a UV-VIS spectrophotogram of the electrolyte from a polarity inversion test, confirms the formation of $\mathrm{RuO}_{4}{ }^{2-}$ as the electrode was cycled [29,30]. In addition to the absorption peak at $465 \mathrm{~nm}$ the electrolyte had the characteristic yellow-brown discoloring developed during the cycled polarity inversion test, which was not the case when plain cathodic or anodic polarization was applied. Although not observed in the cyclic voltammogram in Fig. 4, it is possible that ruthenium species with higher oxidation states $\left(\mathrm{Ru}^{7+}, \mathrm{Ru}^{8+}\right.$ etc. $)$ also were obtained during the corrosion process [14,25], but those peaks would be masked in the region for oxidation of $\mathrm{Ni}^{2+}$ to $\mathrm{Ni}^{3+}$ and the oxygen evolution reaction.

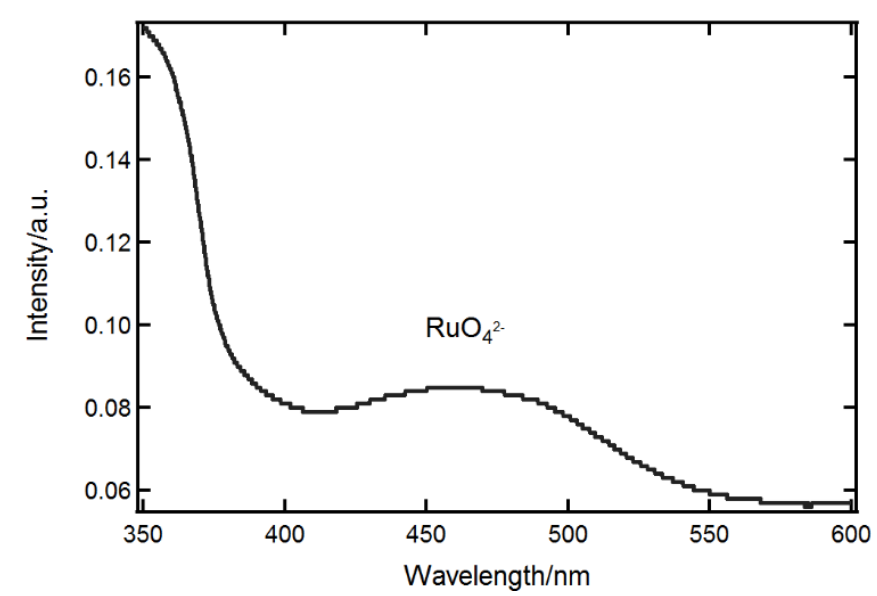

Fig. 5. UV-VIS spectrophotometry performed on the electrolyte $\left(8 \mathrm{M} \mathrm{NaOH}\right.$ at $\left.90{ }^{\circ} \mathrm{C}\right)$ after a polarity inversion test. The absorption peak found at $465 \mathrm{~nm}$ is typical for ruthenate ions $\left(\mathrm{RuO}_{4}^{2-}\right)[25,29,30]$.

The effect of HER, OER, and reverse currents on the crystal phases of $\mathrm{RuO}_{2}$ was studied through XRD and obtained diffractograms are presented in Fig. 6. The main rutile peaks for a fresh sample of a $\mathrm{RuO}_{2}$ coating appear at 27.9, 35.1, 39.8, 54.2, and 57.6 degrees. Additional peaks originate from the substrate and appear as $\mathrm{Ni}$ at 44.5, 51.8, and 76.4 degrees and $\mathrm{NiO}$ at 37.2, 43.3, and 62.9 degrees. At 25.6 degrees there is a small peak that we assign to $\mathrm{Al}_{2} \mathrm{O}_{3}$, which is derived from particles of blasting material incorporated in the Ni surface. A typical 
diffractogram for a $\mathrm{RuO}_{2}$ coating after OER shows no deviation compared to a pristine sample. A diffractogram for a $\mathrm{RuO}_{2}$ coating after HER shows, on the other hand, a substantial change in crystallinity. With increasing duration of the cathodic polarization the rutile 110 peak at 27.9 degrees, enlarged in Fig. 7(a), reduces significantly. Simultaneously there is a growth of a new peak at 26.5 degrees. The corresponding anodic polarization test does not induce any changes of the rutile 110 peak, as shown in Fig. 7(b). This observation suggests that a phase transformation occurs during extensive hydrogen evolution. The peak at 26.5 degrees has been observed before $[3,11]$, although never discussed in detail. It was, however, speculated that this peak originates from hydrated $\mathrm{RuO}_{2}$ or possibly hydroxylated $\mathrm{Ru}$-species formed during strong hydrogen evolution in alkaline medium. Recently, we were able to determine this phase to be more specifically $\mathrm{RuO}(\mathrm{OH})_{2}$ [18]. The diffractogram of the $\mathrm{RuO}_{2}$ coating that has been exposed to the polarity inversion test shows, on the other hand, no peak at 26.5 degrees indicating that the hydroxylated phase, formed during extensive hydrogen evolution, is removed during extensive oxygen evolution, see Fig. 7c. In addition, the rutile 110 peak at 27.9 degrees is not only smaller but also broader indicating that the $\mathrm{RuO}_{2}$ coating consists of particles with smaller crystallite size compared to a pristine sample of $\mathrm{RuO}_{2}$. For example, when HER was applied for six hours followed by OER for six hours, the average diameter of the $\mathrm{RuO}_{2}$ particles decreased from $15.1 \pm 0.2$ to $13.6 \pm 0.4 \mathrm{~nm}$, i.e. a size reduction of $10 \%$.

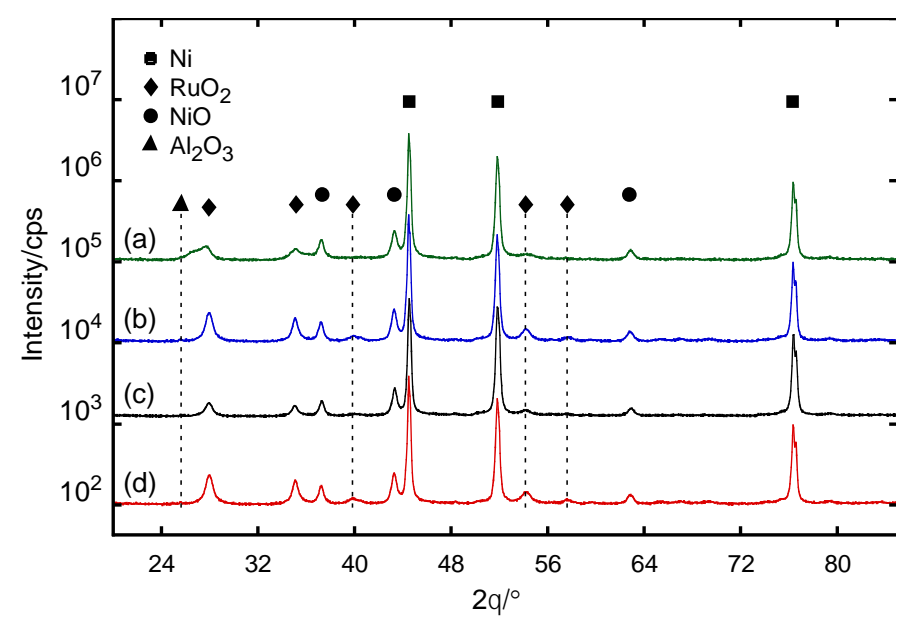

Fig. 6. $\theta-2 \theta$ XRD diffractograms from $\mathrm{RuO}_{2} / \mathrm{Ni}$ electrodes after (a) HER $\left(-6.4 \mathrm{kA} \mathrm{m}^{-2}\right) 6 \mathrm{~h}$, (b) OER (+6.4 kA m$\left.{ }^{-2}\right) 6 \mathrm{~h}$, and (c) HER $\left(-6.4 \mathrm{kA} \mathrm{m}^{-2}\right) 6 \mathrm{~h}+$ OER $\left(+6.4 \mathrm{kA} \mathrm{m}^{-2}\right) 6 \mathrm{~h}$ compared to (d) a pristine $\mathrm{RuO}_{2}$-coating. 

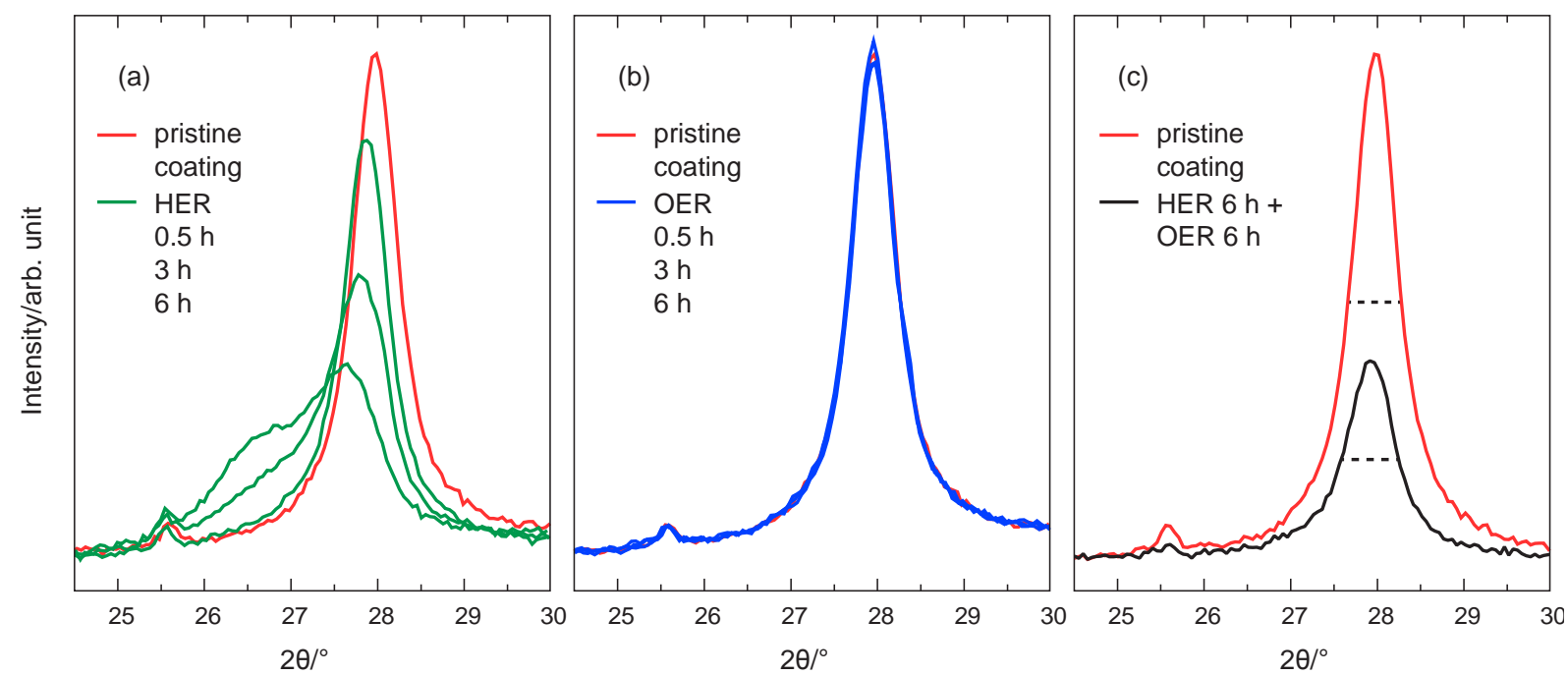

Fig. 7. Rutile 110 peak for $\mathrm{RuO}_{2} / \mathrm{Ni}$ electrode after (a) HER 0.5, 3, and $6 \mathrm{~h}$, (b) OER 0.5, 3, and $6 \mathrm{~h}$, and (c) HER $6 \mathrm{~h}+$ OER $6 \mathrm{~h}$; the current densities were $-6.4 \mathrm{kA} \mathrm{m}^{-2}$ and $+6.4 \mathrm{kA} \mathrm{m}^{-2}$ for HER and OER, respectively. A rutile 110 peak from a pristine coating is included as a reference in all three panels. In (c) the fwhm (dashed line) increases from $0.62 \pm 0.01$ to $0.68 \pm 0.02$ degrees suggesting a reduced particle size after the electrochemical treatment.

\subsection{Effect of anodic currents densities on coating loss in polarity inversion test}

In industrial applications the size of the reverse currents obtained during power shutdowns, e.g. in alkaline water electrolysis, is usually smaller $\left(<0.1 \mathrm{kA} \mathrm{m}^{-2}\right)$ than the anodic currents that we have adopted in the polarity inversion test described in the Experimental section. It is therefore relevant to investigate the effect of the applied anodic current density on the coating loss. Fig. 8 shows the result from a cycled polarity inversion test where the cathodic current density was $-6.4 \mathrm{kA} \mathrm{m}^{-2}$ while the anodic current density was increased from $6,4 \times 10^{-4}$ to 6,4 $\mathrm{kA} \mathrm{m}^{-2}$ for each individual electrodes. The test shows that the electrochemical corrosion starts at relatively low anodic current densities, more specifically at a threshold value of about $2.5 \times 10^{-3} \mathrm{kA} \mathrm{m}^{-2}$. When the applied anodic current density was further increased by an order of magnitude the corrosion process leveled out, most likely because of the limited amount of $\mathrm{RuO}(\mathrm{OH})_{2}$ produced during each cathodic step in the test. This implies that the corrosion process comes to an end when the hydroxylated phase is removed completely during the following anodic step. Once again, no hydroxylated phase could be found in the XRD diffractogram after the final anodic step in the polarity inversion test. However, if the polarity inversion test was stopped after 3.5 cycles, i.e. ending with a cathodic step, $\mathrm{RuO}(\mathrm{OH})_{2}$ was present (data not shown). 


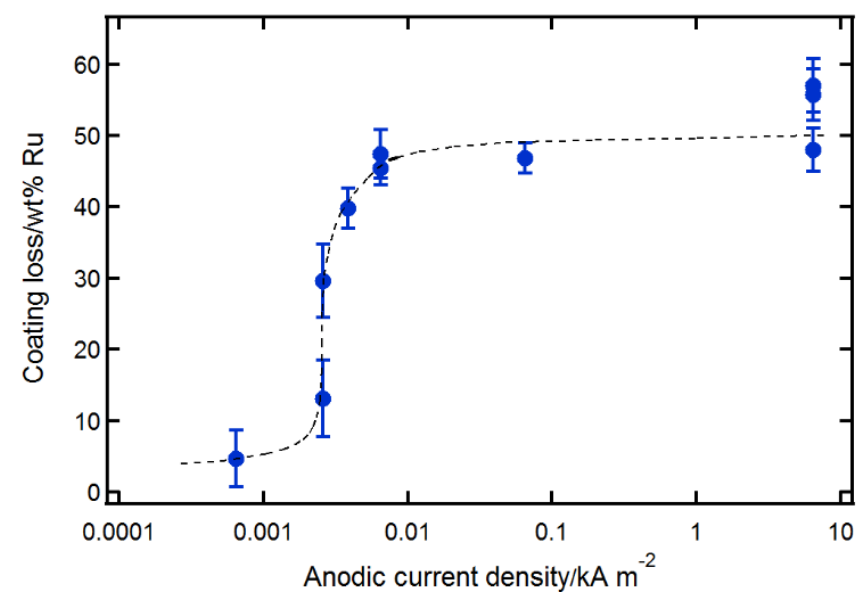

Fig. 8. Coating loss measured with $\mathrm{XRF}$ for individual $\mathrm{RuO}_{2} / \mathrm{Ni}$ electrodes as an effect of anodic current density in a cycled polarity inversion test. Electrolyte: $8 \mathrm{M} \mathrm{NaOH}$ at $90{ }^{\circ} \mathrm{C}$. The error bars represent standard deviation calculated from four XRF measurements at random selected spots on each sample, before and after each test.

\subsection{Description of corrosion process}

From the presented results we can illustrate the corrosion of $\mathrm{RuO}_{2}$-based electrodes subjected to reverse currents in strong alkaline medium. Fig. 9 displays a simple sketch showing that during HER an essential part of the surface of the $\mathrm{RuO}_{2}$ nanoparticles is transformed into hydroxylated Ru-species, which we recently have identified as $\mathrm{RuO}(\mathrm{OH})_{2}$ [18]. When anodic currents are applied after the HER the hydroxylated Ru-species will electrochemically corrode to $\mathrm{RuO}_{4}{ }^{2-}$, and possibly higher oxidation states, that dissolves into the electrolyte leaving an electrode coating with smaller nanoparticles. The corrosion process ceases when all hydroxylated Ru-species are consumed in the anodic step. Further phase transformation followed by electrochemical corrosion will occur if cycling between cathodic and anodic polarization is repeated, resulting in smaller and smaller $\mathrm{RuO}_{2}$ nanoparticles.

In real industrial applications much longer duration of cathodic polarization is expected before any interruption of the process occurs. It is then realistic to believe that the entire $\mathrm{RuO}_{2}$ coating might be transformed into $\mathrm{RuO}(\mathrm{OH})_{2}$ and the worst-case scenario might then be that the entire electrode coating will corrode when the cathode is subjected to reverse currents during unprotected conditions, e.g. no use of polarization rectifiers or poorly working rectifiers during power shutdowns. Other parameters that most likely will influence the rate of hydrogen absorption and formation of $\mathrm{RuO}(\mathrm{OH})_{2}$ during $\mathrm{HER}$, and subsequently the extent of 
corrosion caused by reverse currents, are applied cathodic current density, electrolyte concentration, and temperature.

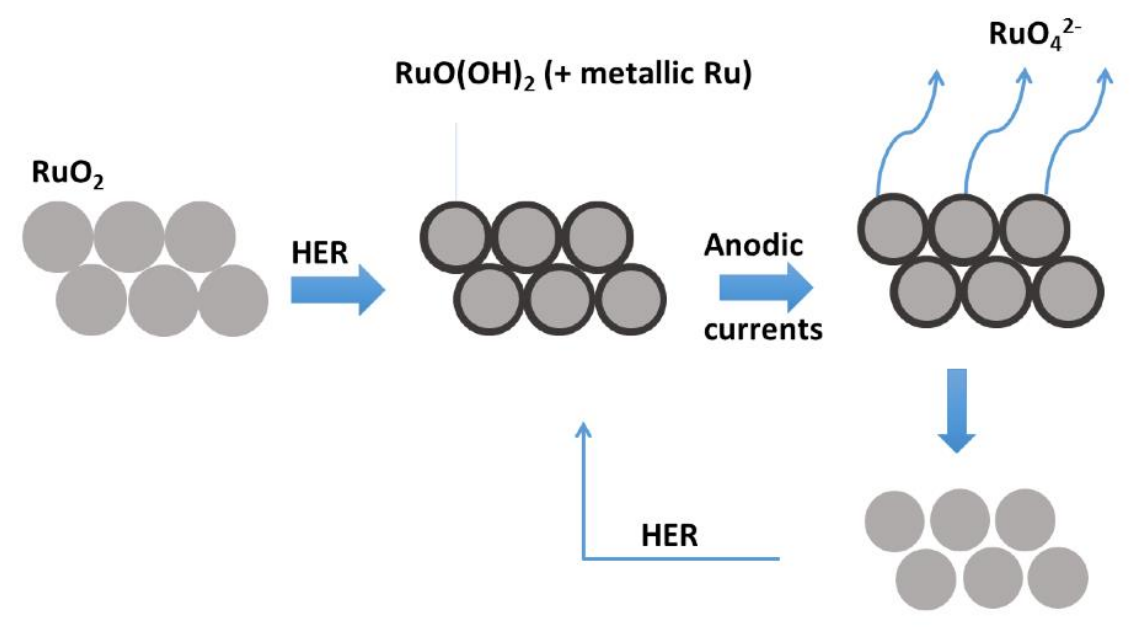

Fig. 9. Simple illustration of the corrosion of $\mathrm{RuO}_{2}$ coatings subjected to polarity inversion after HER in alkaline medium. $\mathrm{RuO}_{2}$ nanoparticles that are exposed to hydrogen evolution develop a shell of $\mathrm{RuO}(\mathrm{OH})_{2}$ (and metallic $\mathrm{Ru}$ ) [18]. Anodic polarization causes oxidation of $\mathrm{RuO}(\mathrm{OH})_{2}$ into $\mathrm{RuO}_{4}{ }^{2-}$ that dissolves into the electrolyte. The corrosion process comes to an end when all $\mathrm{RuO}(\mathrm{OH})_{2}$ is oxidized and the remaining coating consists of $\mathrm{RuO}_{2}$ with smaller nanoparticle sizes.

\section{Conclusions}

In this work we show why $\mathrm{RuO}_{2}$-based coatings in strong alkaline environments are sensitive to reverse currents. Because of the extent of hydrogen exposure during cathodic polarization, a substantial amount of the $\mathrm{RuO}_{2}$ coating is transformed into hydroxylated phases that are far more sensitive to revere currents compared to $\mathrm{RuO}_{2}$ coating subjected to only anodic polarization. When an anodic current is introduced after extensive hydrogen evolution the hydroxylated $\mathrm{Ru}$-species oxidizes and form $\mathrm{Ru}^{6+}$ species and possibly compounds with even higher oxidation states. During the studied time scale, the corrosion process ceased as soon as all hydroxylated phase was consumed, leaving an electrode coating with smaller $\mathrm{RuO}_{2}$ nanoparticles. 


\section{Acknowledgments}

The Swedish Research Council (project nr. 2007-5059) is acknowledged for funding this study. The study has partly been accomplished through funding from the European Research Council under the European Communities Seventh Framework Program (FP7/20072013)/ERC Grant agreement no. [258509], the Swedish Research Council (VR) grant no. 642-2013-8020, and the KAW Fellowship program. Ellen Baken, FEI and Heiner Jaksch, Carl Zeiss NTS are highly acknowledged for providing the cross-section and high-resolution SEM images, respectively, and the assistance from Bernth Nordin, Permascand, with pre-treatment of some electrodes was very much appreciated. SH also thanks Joakim Bäckström, Håkan Olin and Torbjörn Carlberg from Mid-Sweden University, Ann Cornell, Rasmus Karlsson and Göran Lindbergh from KTH Royal Technical Institute, and Lars-Erik Bergman, Ingemar Johansson and John Gustavsson from Permascand for valuable discussions. 


\section{References}

[1] T.F. O'Brien, T.V. Bommaraju, F. Hine, Handbook of chlor-alkali technology. Volume I: Fundamentals, Springer Science+Business Media, New York, 2005.

[2] T.F. O'Brien, T.V. Bommaraju, F. Hine, Handbook of chlor-alkali technology. Volume II: Brine treatment and cell-operation, Springer Science+Business Media, New York, 2005.

[3] C. Iwakura, M. Tanaka, S. Nakamatsu, H. Inoue, M. Matsuoka, N. Furukawa, Electrochemical properties of $\mathrm{Ni} /\left(\mathrm{Ni}+\mathrm{RuO}_{2}\right)$ active cathodes for hydrogen evolution in chloralkali electrolysis, Electrochim. Acta 40 (1995) 977.

[4] M.B.I. Janjua, R.L. Le Roy, Electrocatalyst performance in industrial water electrolysers, Int. J. Hydrogen Energy 10 (1985) 11.

[5] B. Børresen, G. Hagen, R. Tunold, Hydrogen evolution on $\mathrm{Ru}_{\mathrm{x}} \mathrm{Ti}_{1-\mathrm{x}} \mathrm{O}_{2}$ in $0.5 \mathrm{M} \mathrm{H}_{2} \mathrm{SO}_{4}$, Electrochim. Acta 47 (2002) 1819.

[6] V.D. Jović, U. Lačnjevac, B.M. Jović, N.V. Krstajić, Service life test of non-noble metal composite cathodes for hydrogen evolution in sodium hydroxide solution, Electrochim. Acta 63 (2012) 124.

[7] S. Ardizzone, G. Fregonara, S. Trasatti, Influence of hydrogen evolution on the voltammetric charge of $\mathrm{RuO}_{2}$ electrodes, J. Electroanal. Chem. 266 (1989) 191.

[8] M. Blouin, D. Guay, Activation of ruthenium dioxide, iridium dioxide, and mixed $\mathrm{Ru}_{\mathrm{x}} \mathrm{Ir}_{1-\mathrm{x}}$ oxide electrodes during cathodic polarization and hydrogen evolution, J. Electrochem. Soc. 144 (1997) 573.

[9] L.D. Burke, N.S. Naser, Metastability and electrocatalytic activity of ruthenium dioxide cathodes used in water electrolysis cells, J. Appl. Electrochem. 35 (2005) 931.

[10] C. Chabanier, D. Guay, Activation and hydrogen absorption in thermally prepared $\mathrm{RuO}_{2}$ and $\mathrm{IrO}_{2}$, J. Electroanal. Chem. 570 (2004) 13. 
[11] T. Hachiya, T. Sasaki, K. Tsuchida, H. Houda, Ruthenium oxide cathodes for chloralkali electrolysis, ECS Trans. 16 (2009) 31.

[12] L. Chen, D. Guay, F.H. Pollak, F. Lévy, AFM observation of surface activation of ruthenium oxide electrodes during hydrogen evolution, J. Electroanal. Chem. 429 (1997) 185.

[13] A. Cornell, D. Simonsson, ruthenium dioxide as cathode material for hydrogen evolution in hydroxide and chlorate solutions, J. Electrochem. Soc. 140 (1993) 3123.

[14] M. Pourbaix, Atlas of electrochemical equilibria in aqueous solutions (Engl. Ed.), Pergamon press, Oxford, 1966.

[15] N. Takeno, Atlas of Eh-pH diagrams; Intercomparison of thermodynamic databases, Geological Survey of Japan Open File Report No. 419, 2005.

[16] E.R. Kötz, J. Stucki, Ruthenium dioxide as a hydrogen-evolving cathode, J. Appl. Electrochem. 17 (1987) 1190.

[17] D. Rochefort, P. Dabo, D. Guay, P.M.A. Sherwood, XPS investigations of thermally prepared $\mathrm{RuO}_{2}$ electrodes in reductive conditions, Electrochim. Acta 48 (2003) 4245.

[18] L.-Å. Näslund, Á.S. Ingason, S. Holmin, R. Rosen, Formation of $\mathrm{RuO}(\mathrm{OH})_{2}$ on $\mathrm{RuO}_{2}-$ based electrodes for hydrogen production, J. Phys. Chem. C. 118 (2014) 15315.

[19] P. Shrivastava, M.S. Moats, Wet film application techniques and their effects on the stability of $\mathrm{RuO}_{2}-\mathrm{TiO}_{2}$ coated titanium anodes, J. Appl. Electrochem. 39 (2009) 107.

[20] C. Hummelgård, J. Gustavsson, A. Cornell, H. Olin, J. Bäckström, Spin coated titaniumruthenium oxide thin films, Thin Solid Films 536 (2013) 74.

[21] H.P. Klug, L.-E. Alexander, X-ray diffraction procedures: for polycrystalline and amorphous materials, 2nd ed. Wiley, New York, 1974. 
[22] C. Malmgren, A.K. Eriksson, A. Cornell, J. Bäckström, S. Eriksson, H. Olin, Nanocrystallinity in $\mathrm{RuO}_{2}$ coatings-influence of precursor and preparation temperature, Thin Solid Films 518 (2010) 3615.

[23] L. Roué, D. Guay, R. Schulz, Hydrogen electrosorption in nanocrystalline Ti-based alloys, J. Electroanal. Chem. Interfacial. Electrochem. 480 (2000) 64.

[24] L.D. Burke, O.J. Murphy, The electrochemical behaviour of $\mathrm{RuO}_{2}$-based metal oxide anodes in base, J. Electroanal. Chem. 109 (1980) 199.

[25] J. Juodkazytė, R. Vilkauskaitè, B. Šebeka, K. Juodkazis, Difference between surface electrochemistry of ruthenium and $\mathrm{RuO}_{2}$ electrodes, Trans. Inst. Met. Finish. 85 (2007) 194.

[26] M.A. Domínguez-Crespo, A.M. Torres-Huerta, B. Brachetti-Sibaja, A. Flores-Vela, Electrochemical performance of $\mathrm{Ni}-\mathrm{RE}(\mathrm{RE}=$ rare earth) as electrode material for hydrogen evolution in alkaline medium, Int. J. Hydrogen Energy 36 (2011) 135.

[27] M.E.G. Lyons, L. Russell, M. O’Brien, R.L. Doyle, I. Godwin, M.P. Brandon, Redox switching and oxygen evolution at hydrous oxyhydroxide modified nickel electrodes in aqueous alkaline solution: effect of hydrous oxide thickness and base concentration, Int. J. Electrochem. Sci. 7 (2012) 2710.

[28] W. O’Grady, C. Iwakura, J. Huang, E. Yeager, Ruthenium oxide catalysts for the oxygen electrode, in: M.W. Breiter (Ed.), Proceedings of the Symposium on Electrocatalysis, Princeton, 1974, p. 286.

[29] R.E. Connick, C.R. Hurley, Chemistry of Ru(VI), -(VII) and -(VIII), Reactions, oxidation potentials and spectra, J. Am. Chem. Soc. 74 (1952) 5012.

[30] L. Roué, D. Guay, R. Schulz, Electrochemical behavior of nanocrystalline $\mathrm{Ti}_{2} \mathrm{RuFe}$ alloy prepared by high energy ball-milling, J. Electroanal. Chem. 455 (1998) 83. 
